\title{
Cinematic reproduction as multimodal composition in first-year composition
}

\author{
Rachel McCabe \\ Department of English, La Salle University
}

\begin{abstract}
This case study introduces an assignment from a large midwestern university first-year composition (FYC) program, which emphasizes analytical writing by introducing students to a series of increasingly layered texts, including film. Teaching multi-perspective, evidence-based visual and textual analysis has many advantages for student writers. For students to see textual constructedness, the instructor requires they remake film scenes using their cellphones, employing and then articulating their use of generic conventions. This article details the original assignment and tracks its evolution, brought about by students' innovations. One group's project, a scene from The Shining (1980), highlights multimodal re-creation's capacity to help students re-envision and more fully analyze cinematic elements, adding depth and specificity to their analytical writing.
\end{abstract}

Keywords: multimodal production, video, film, recreation, first-year composition

\section{Introduction}

During my time teaching first-year composition at a large midwestern university, ${ }^{1}$ my syllabi asked students to write about a variety of texts. ${ }^{2}$ These syllabi, organized in large part by the required assignments of the English Department's Composition Program and the standards set by the Council of Writing Program Administrators, ${ }^{3}$ focused on reading traditional texts ${ }^{4}$ early on in the semester and built outward to visual analysis. In exploring how to get students to turn their pre-developed visual literacy into academic analysis and writing, film production became an optional component in the assignment sequence. This case study outlines how I shifted a

\footnotetext{
${ }^{1}$ Indiana University is a public four-year university located in Bloomington, Indiana. It averages 33,000 undergraduate students and 10,000 graduate students each academic year. According to the university's website, the predominant demographic of the university's undergraduate population is white students from the midwestern United States, with $25 \%$ of students identifying as part of a minority and international students making up $6 \%$ of the student body. Most first-year college students have completed high school the semester before they begin ("Student Diversity").

${ }^{2}$ First-Year Composition is a required writing course in most American universities. It acclimates students to academic writing while teaching rhetorical strategies and reading skills required not only for writing courses, but also for any writing in their university coursework. At some universities it is a one-semester course, but in others it is part of a larger writing course sequence.

3 The Council of Writing Program Administrators suggests in their "WPA Outcomes Statement for First-Year Composition" that first-year writing courses focus on building rhetorical awareness and critical thinking, reading, and writing skills through a process-oriented model of writing instruction" ("WPA").

${ }^{4}$ Examples include chapters from John Berger's Ways of Seeing, Michel Foucault's Discipline and Punish, and Gloria Anzaldúa's Borderlands. All of these readings are meant to be introductions to academic reading and are written by, and for, a variety of academic and non-academic audiences.
} 
visual production assignment toward visual reproduction, as well as the benefits this shift had on the student writing process.

By examining the changes to this assignment and the impact of film reproduction in my writing courses, I demonstrate the benefits of assignment flexibility, for it leaves room for student creativity and innovation. I also argue for the benefits of multimodal production in the composition classroom and show how recreation can reduce time while maximizing student engagement within film genre exploration. The included final product, while showing the outcome of the assignment's final iteration, also reveals the fascinating ways that scene recreation can generate sophisticated analysis of films. In the process, the analytical skills developed in the exercise led students to more detailed observations, which were then reflected in their writing about film. This multimodal exercise highlights the benefits of flexible assignment design and the potentially exciting impact of visual production on student analysis and writing.

\section{Research and practice: a brief review}

During my time teaching at Indiana University, I had the privilege of both being trained by, and working with, a team of composition instructors devoted to exploring the capability of film in the writing classroom. ${ }^{5}$ The benefits of writing about film have, for decades, been examined in composition studies. Ellen Bishop (1999), Daniel Wild (1999), and Henry Giroux (2001) have written about the complex relationship between film and student writing. In "Breaking into the Movies: Pedagogy and the Politics of Film," Giroux claims: "As a form of public pedagogy, film combines entertainment and politics, and, as I have attempted to argue, lays claim to public memory (though in contested ways given the existence of distinctly varied social and cultural formations)" (p.588). ${ }^{6}$ This meeting place of high and low art within a structured narrative makes film feel culturally significant, not only to broader audiences, but also to students. Its unique combination of visual text, narrative, and cultural representation make it a powerful medium for student writing.

Filmmaking and the use of film analysis are critical to the development of skills that I see as parallel to the traditional writing heuristics we teach to students in our first-year curriculum. Daniel Wild (op.cit) explains in his essay "Writing Images: Some Notes on Film in the Composition Classroom" that, while revision helps students to see their work from a new perspective, film literally asks students to see and think in different ways, a difference they can then articulate in their writing (p.23). Unlike other forms of multimodal production, film facilitates this "act of seeing," which proves serviceable when we ask students, in their writing, to see the world through a perspective other than their own. This production assignment became a touchstone in our classroom discussion about how a director's cinematic choices shape our viewing experience.

\footnotetext{
5 This primarily took the form of written analysis of film, developed and revised over time by Composition Directors Christine Farris, John Schilb, and Dana Anderson.

6 In the process, this public memory comes from two sources: "Mining the twin operations of desire and nostalgia, they are also sites of educated hopes and hyper-mediated experiences that connect the personal and the social by bridging the contradictory and overlapping relations between private discourses and public life" (Giroux 588).
} 
This assignment also demonstrates the benefits of the experiential challenges that come with the multimodal production process explored by Jody Shipka. As Shipka states in Composition Made Whole (2011), the now famous ballet shoes “....allowed [Shipka] to see, and so to understand, the final product in relation to the complex and highly rigorous decision-making processes the student employed while producing this text" (p.3). In the same way, this video assignment allowed me to see the complexity of my students' visual literacy. Their careful analysis of the original text was reflected in the project they made, even if they couldn't necessarily move to the metacognitive step of explaining why they had made the choices they did.

\section{Context}

One of the central obstacles was integrating the complex visual knowledge students bring to their writing courses with the vocabulary necessary to talk about visual analysis effectively. ${ }^{7}$ While the majority of my students were adept at filming content with their smartphones, most students thought of films as polished products which existed outside of the process-oriented work of other creative processes like writing. Similarly, while most students could list film genres and knew some of the conventions of genres, they gave little thought to the specific choices and details that constructed these tropes. I implemented an assignment in which students were assigned cinema genres and asked them to film short scenes that they would expect to find within that genre. This assignment was an optional part of the curriculum, but I saw value in involving students in the cinematic production process.

The goal was to help students make connections between the composing process of writing and the composing/directing of film. Rather than see films or visual media as polished products, having students write, stage, and edit a short production would allow them to experience all of the steps and choices that go into film scenes. Once these choices became visible to them, students would be able to articulate more clearly in their writing the rhetorical impacts of these choices.

Once assigned a genre (such as 'action' or 'horror'), students were given a worksheet that asked them to choose their role in the group project and to map out the characteristics of their assigned genre, their characters and their setting. After the scene had been filmed on one group member's phone, students answered questions on the same worksheet asking them to summarize the scene they had created and to analyze the details they had chosen to feature. After one class period devoted to filming the assignment, the next class meeting began with a 'class screening'. The members of each group stood at the front of the class and played their

\footnotetext{
${ }^{7}$ Building on the analytical skills required for visual analysis, former Graduate Assistant Director of FYC Jennifer Juszkiewicz designed an optional assignment that asked students to create a series of photo stills from an imagined film within an assigned genre. This assignment was meant to get students thinking about the ways in which generic expectations help us to analyze and interpret films. Students were given different toys and asked to take a series of photos that, when shown together, represented a possible scene from a romantic comedy. The accompanying worksheet asked students to designate their different roles in the creation process, including director, cinematographer, set designer and casting director. It also asked students to explain how the choices they made represented the generic conventions of the type of film they were exploring. This assignment was a starting point to think about how production could get students to demonstrate visually their knowledge of these generic conventions.
} 
scene for us on the classroom's screen projector; afterward, they explained their choices and why they felt their scene represented the conventions of their assigned genre.

This assignment helped students see the components of a film scene and led into the next assignment, in which students would watch a film and choose a specific scene to write about. ${ }^{8}$ Once they located an interesting scene, they would analyze the visual details and draw a claim about the director's goals. Asking students formatively to plan and film short scenes beforehand exposed the complex processes that go into the creation of the films, television shows, and YouTube videos they watch on a regular basis, illustrating how these (often) seamless final products are the result of innumerable rhetorically-driven decisions. Owing to the dramatic shifts in student access to smartphones, it seemed feasible to divide students into small groups, making sure that at least one student was willing to use her/his phone to film the project, and ask each group to create a film scene. ${ }^{9}$ The assessment of this assignment came in three spaces: the final cinematic product, the group's description of its work, and the subsequent written analysis of a film scene. While the final product and presentation weren't graded, subsequent writing was evaluated and graded on the basis of the student's written argument and ability to draw connections between the details of the scene and the director's overall goal.

\section{Implementation}

After teaching this assignment for two semesters, I began to notice several patterns develop:

1) Students often couldn't necessarily articulate the reasons why they executed specific cinematic decisions other than to focus on the technical limitations of the production process.

2) The drafting phase of the project was very time-consuming and often took up far more time than the filming stage.

3) In many cases, even though students couldn't clearly articulate the cinematic choices that went into their own projects, their subsequent written cinematic analyses of the films we watched in class often included more cinematic details and devoted more time to explaining how these details had led them to the conclusions of their analysis.

\footnotetext{
8 The required assignment in the 'Film Unit' of the curriculum was an essay in which students applied the heuristic of "using a source as a lens" from Writing Analytically (63-68) to synthesize a central concept from the reading and then use this concept to see a film scene in a new light. For example, students who read Michel Foucault's "Panopticism" could apply the idea of the panopticon to Alfred Hitchcock's Rear Window to read the film's voyeurism and visual power in Foucault's terms.

${ }^{9}$ As Steve Wheeler and Richard Gerver describe in Learning with 'E's : Educational Theory and Practice in the Digital Age, the technological landscape of the composition classroom has shifted dramatically with the seeming ubiquity of personal technology and internet access. In both formal and informal settings, "students are taking greater responsibility for their own learning, creating their own learning and discussion spaces online outside of the auspices of the parent institution. They are engaged in unprecedented levels of peer learning, supporting each other through a variety of new technologies and personal tools" (p.33). Allowing students to use their smartphones to film short scenes was not only a possibility (since each group had access to at least three phones with filming capability), but also an activity that students were deeply engaged in. By 2014, most students were arriving to class with at least some technological literacy on how to film content with their smartphones and then upload it to their computer.
} 
While the benefits of the production process seemed clear, I continued to look for ways to help students get as much value out of the assignment as possible.

\section{Step 1: Limiting assignment questions to maximize planning time}

I limited the questions on the worksheet and focused more on the planning stages to help students structure this time more effectively. I also asked them fewer response questions and instead had all the members of each group present any information they wanted to share when they showed their video to the class. The flexibility of this presentation component allowed the class to point out aspects of each group's video that worked well for their assigned genre. This conversation helped foster a communal spirit around the film creations. ${ }^{10}$

\section{Step 2: Ensuring flexibility within the assignment}

Because of the flexible nature of the assignment (and assignment sheet), students began asking if they could alter the assignment: in some cases, making short films so they could follow a full narrative arc rather than segmenting the content. Groups asked if they could make trailers for their film genres, which proved to be extremely effective, since they allowed us to discuss both genre conventions and how they are emphasized in film advertising. Originally, I cut up paper figures so that students wouldn't need to act in the films if they didn't want to perform on camera. However, as their projects became more and more elaborate, some students asked to forgo the paper figures and act in their videos themselves.

\section{Step 3: Supporting student investment and facilitating 'bring your own device' (BYOD)}

In addition, by allowing them to use whatever software and cinematic tools with which they were comfortable, little technological instruction was necessary. As Steve Wheeler and Richard Gerver (2015) note, "Those who do support BYOD for students will need to invest significant time and resources into ensuring cross-platform operability and seamless delivery to students' personal technologies" (pp.37-38). I deliberately avoided any explicit expectation of technological literacy or access and, instead, structured groups loosely, allowing for students to self-select the tasks of the assignment they wanted to complete. Groups quickly determined who had the most cinematic experience or interest and divided the different levels of cinematic creation accordingly. ${ }^{11}$ As a result, students were able to showcase different skill sets that might not have been shared in more traditional writing assignments.

\footnotetext{
${ }^{10}$ According to Eileen Carnell's 2007 article "Characteristics of Effective Teaching and Learning," the central characteristics of effective teaching and learning are that the learning process is transparent, brought about through dialogue, and built by a community of learners in order to generate knowledge (pp.30-33). This project encapsulated these elements by exposing the unknown composition elements of film-making, creating a dialogue between the students, their texts and the class as a whole and building a sense of community around the creative elements of their work.

11 It should be noted that this self-selection process occurred not only for the technologically savvy students, but also for those with artistic talent and other skill sets that became highlighted during the creation process.
} 


\section{Step 4: Supporting different group needs to maximize creativity}

Over time, I noticed that, while some groups struggled with the lack of directions, other groups thrived under less specific guidance. As I continued to think through this difference in the final products students generated, I noticed a parallel to Lars von Trier's (2003) documentary The Five Obstructions. In the documentary, Jørgen Leth must recreate his film The Perfect Human (1968) with different limitations set by von Trier. Leth thrives under the rules of the documentary, specifically because each project has only one obstruction he must work within. The limited directions allow for maximum creative potential. The film's projects parallel the assignment I designed, in which students had unlimited potential within their assigned film genre. While all groups could speak to valuable production-related lessons they had learned, the final product of groups of students with a stronger belief in their own creative ability was often more nuanced than the final product of groups of students who vocalized concerns that film production was something outside of their skill set. To mitigate this difference, I spent more time helping students who described themselves as feeling "less creative" to brainstorm their scenes, while I let more confident students explore their ideas in whatever ways they were excited to try.

\section{Step 5: Rewriting reproductions}

After multiple rounds of revision, the assignment's parameters continued to shift, but its focus on genre reconstruction remained the same. In 2017, I assigned one group the 'horror' genre and asked that they compose a scene or trailer (since I had expanded the assignment on the basis of the work of previous groups). When we reconvened to watch the films, the 'horror' group presented its work: the group had brought a bicycle into our building and recreated the famous scene from Stanley Kubrick's The Shining (1980), in which Danny rides down the hotel's hallway and sees the ghosts of two murdered girls. Because the video showed our adult classmate covering his eyes as two paper girls were shredded with a pair of scissors, the class roared with laughter. ${ }^{12}$

When I asked the group how many times they had to watch the scene in order to execute this project, they said they'd watched the clip at least eight times and talked about how difficult it was to match the camera angles and cuts that Kubrick chose to use in his film. They also talked about which cinematic elements they manipulated to adjust to the limited resources they had, which led into a fruitful discussion about the ways that re-creation can often have a comedic effect. Students laughed because they were familiar with the original scene and seeing their classmate imitate the actions of a little boy, along with the substitution of cut-up paper dolls for murdered children, made the content much lighter. In addition to the pleasure experienced by watching this comedic remake of Kubrick's horror scene, they were also able to identify why the re-creation made them laugh. In our discussion, they talked about the original scene as well as the re-creation by pointing to specific cinematic details that led to both the horrifying impact of Kubrick's scene and the comedic results of their classmates' reproduction.

\footnotetext{
12 The student work can be viewed here: [https://www.youtube.com/watch?v=eTsMnRmvKC0\&feature=emb title [Accessed: 18 November 2020].
} 


\section{Evaluation}

The central success of this assignment was the re-watching of the film scene. In order to think through the choices Kubrick made, the group watched the scene many times. This is exactly the type of work visual analysis asks for in writing: the careful review of a specific moment to break down and expand upon the cinematic elements at play. In turn, I adjusted the assignment and, in subsequent courses, I asked for the reconstruction of a well-known film scene. This cut down on the prep time and allowed students to think specifically about the production techniques they would utilize, rather than spending time inventing a film. Bringing multimodal composition into the writing classroom may well feel like time away from other necessary reading and writing skills, so balancing time constraints while maximizing room for innovation can be challenging. Imitation allowed for creative re-imagining of the film scene, but also limited the most timeconsuming part of the original assignment: the imagining of a scene from a genre. It also facilitated student innovation within the rhetorical borders of the assigned film scene.

\section{Methods}

The three points of feedback for this assignment were the final product of the videos, subsequent class discussion, and the following written assignment on cinematic analysis. As the assignment became more flexible and allowed students to create a short film or trailer, the 'creativity gap' began to develop between groups: while the final products of some groups were more detailed and more visually advanced, other groups struggled to capture their genre's conventions using the available resources. That said, all groups still generally showed more detailed responses in their subsequent writing on film. There was also a consistent disconnect between final products and group presentations of their work. Some groups were better at explaining the ways their final product developed (regardless of how the video actually looked), while other groups had phenomenal final products and couldn't explain the choices they made. Class discussion was necessary to push all students to see some of the rhetorical impacts they didn't anticipate.

When these three methods were used to evaluate the reproduction assignment, several changes were immediately evident. First, the creativity gap was dramatically reduced because no group had to invent a scene, trailer, or short film from scratch. By watching the assigned scenes together, each group started at the same 'creativity level'. While students were still not necessarily able to explain clearly all of their choices during the presentations of their videos, the discussions between presenters and the larger class were more detailed because every member had seen the starting point for each project. By watching the original film scenes together, every student saw the starting material for each group's video and they were able to ask about the specific interpretation methods used by the students presenting. This shift in the assignment allowed students to derive the same benefits for their subsequent writing assignments (using specific cinematic details as evidence, drawing claims about the film's rhetorical impact, etc.) while reducing the time spent trying to invent a film genre from scratch. 


\section{Limitations}

The success of my students' reproduction assignment was, in some ways, a result of their economic and educational demographics. Each semester at Indiana University, I taught students who were generally middle-class, white, and with some previous experience of multimodal or creative assignments. While one or two students even had experience with video editing or production software, the majority were familiar with recording content on their smartphones (and almost all had these). I structured the groups in a way that would divide up students who self-identified as creative or artistic, but this didn't always evenly disperse the 'creative' students - having even one group member with filming experience could greatly influence that group's final product.

In addition, my feedback from students encompassed a small data set. I worked with about 100 students in all between the start of my experiments with scene-creation projects and my second time teaching the re-creation assignment. While I was able to see patterns within student presentations and writing over these semesters, the limited data set and consistency of student demographics should be considered when reviewing these findings.

\section{The Four Conclusions}

\section{Conclusion 1:}

In addition to shaping our classroom community, this assignment helped students conceptualize the larger academic community with which they were in conversation. In Joseph Harris's textbook Rewriting: How to Do Things with Texts (2006) the second chapter on 'forwarding' academic writing suggests that students should resist the pressure to invent something new out of thin air. Instead, he suggests they see their writing as part of a larger academic conversation. He explains that the metaphor of "writing as conversation" is beneficial because "[i]t highlights the social aspects of intellectual work, the ways in which academic writing responds to the texts and ideas of others" (p.35). Specifically, the reproduction of film served as an example of extending the cinematic and cultural conversation produced by Kubrick's original text. This allowed me again to connect the film-making process to the traditional writing process for student essays: this assignment was a way of visually quoting Kubrick's work by adding a comedic lens.

In von Trier's The Five Obstructions (2003), Leth demonstrates the creative potential of thinking through an idea under new circumstances. This act of re-creation allows him to focus more on how he's constructing each new version of his film than any other creative factor. Similarly, students who recreated Kubrick's famous scene focused more on the camera angle, framing and editing than any other group that semester, primarily because the original film provided them with a different starting point from that of their peers.

In the process, attention to these editing techniques and their relationship to the film's genre helped students to articulate the specific details that led to their analysis of the scene in their writing. Students went from making generalizations about visual texts to drawing specific claims from visual details. For example, students writing about Alfred Hitchcock's Vertigo (1958) went 
from using phrases such as "The green lighting in the hotel room gives the room an eerie look" to detailed paragraphs that explain the rhetorical impact of these cinematic effects:

The green lighting in the room pours in from the neon sign outside, making the otherwise neutral room glow. This green haze, (green being a color associated with rebirth) fills the frame as Judy is seemingly reborn as Madeline when she reenters the room. Judy also appears hazy and translucent, creating the feeling that the ghost of Madeline is walking through the doorway. Hitchcock uses the lighting to show how Scottie's desire of bringing back Madeline has been fulfilled. ${ }^{13}$

This level of detail increased once students saw visual texts as the result of rhetorical choices rather than texts that exist as finished products. For me, this was evidence of improved student analysis of visual texts that then appeared in their writing. This was accomplished both by practicing visual analysis as a class and through this multimodal assignment.

\section{Conclusion 2:}

Re-creating an existing film scene helped level the 'creativity curve'. As was noted in previous iterations of this assignment, some students thrived under the lack of structure when assigned to create a scene they would expect to find within a specific film genre. However, others found this task difficult, particularly students who described themselves as not being 'creative types'. While film production had a consistently positive impact on student thinking and writing, the differences in the final product showed that groups with students describing themselves as 'artistic' often found it easier to capture their ideas on video.

Asking students to recreate a famous film scene leveled this 'creativity curve'. To begin the assignment, I began by screening the assigned scenes for the class. Each group was then given a worksheet to help them divide tasks to recreate the assigned scene. Some students were excited by the idea of making significant changes in their scene, while others were interested in executing a reproduction that modelled itself as much as possible on the original scene. All groups had to consider resource limitations and the limited amount of time with which they had to work, but ultimately could be as creative as they wanted to be in their final product. Reproduction was a mode all students could access. Students experienced the benefits of cinematic production: they paid close attention to the original scene and tried to capture the elements of this original work by thinking about the rhetorical impact of lighting, sound, casting, set design, and editing.

\footnotetext{
13 These two sentences are paraphrased from student work on the 'film scene analysis' assignment that followed the scene recreation assignment in Spring 2018.
} 


\section{Conclusion 3:}

Throughout the evolution of this assignment, my flexibility as an instructor was rewarded. Particularly in my initial years as an instructor, I saw it as my job to make sure students were following the directions I wrote out in assignments. However, the more creative structure of this assignment showed me the ways in which students can potentially exceed expectations when given the space to do so. Just as The Five Obstructions (2003) demonstrated the benefits of reproduction, so this approach reveals the ways in which creative work thrives with limited obstacles and maximum flexibility of interpretation.

This flexibility was balanced with clearer directions for the assignment. Rather than setting students free to create a film or film scene, the reproduction assignment included more specific expectations. Specificity is what then enabled creativity, as long as students produced a final product that met the assignment's goals. This model of flexibility could be beneficial, not only to writing instructors, but also to any faculty looking to incorporate multimodal assignments into their curriculum.

While not all FYC curriculums have the flexibility to include assignments such as these, the basic heuristics around reproduction and multimodality are fairly accessible and can be built into classroom activities in small ways. These could include recreating Instagram posts, YouTube videos, or photographs. Willingness to include the visual and technological literacy students bring with them to the composition classroom paid off in dividends, not only in the visual analysis they were able to produce, but in the development of a classroom community in which multiple skills and viewpoints were considered valuable.

\section{Conclusion 4:}

My students, like Shipka's student, exposed their visual literacy through the details of their videos. The careful editing, filming, and acting all stress their close viewing of the original product. According to Shipka (op.cit.), "Having gained a greater appreciation of the contextual or situational aspects of communicative practice...students would prove themselves to be more flexible and reflected communications than students enrolled in traditional freshman courses" (p.26). While this assignment wasn't a required one in the standardized first-year curriculum at my university, I recommended - and continued to recommend - this assignment to instructors as a way to develop, showcase, and reward students for the visual literacy they bring with them to their writing classes.

Many of the benefits, then, came not only from the creation of student videos but also their presentation to the rest of the class. When considering the benefits of film analysis in the writing classroom, Wild (op.cit) claims that the goal of writing courses should move beyond teaching students grammar and rhetorical writing skills. In the process, "[t]he primary focus thus becomes the production of writing that moves toward a self-reflexive understanding of its discursive functions, an understanding of the student writers' role within this discourse and an emerging sense of the scope of intellectual practices in writing" (pp. 22-23). In my classroom, this reflexivity came both in the production of the multimodal product and in its delivery to the rest of the class: students may not have been able to vocalize why the changes they made in adapting 
a scene helped them achieve a particular rhetorical effect, so their classmates helped them come to these realizations by explaining the impact the videos had on them as viewers.

\section{Reference list}

Anzaldúa, Gloria. (1987) Borderlands = La Frontera: The New Mestiza. San Francisco:

Spinsters/Aunt Lute Publishing. ISBN: 978-0933216259.

Berger, J., Blomberg, S., Fox, C., Dibb, M., and Hollis, R. (1973) Ways of Seeing. London: British Broadcasting Company and Penguin Books. ISBN: 978-0140135152.

Bishop, E. (1999) Cinema-(to)-Graphy: Film and Writing in Contemporary Composition Courses. Portsmouth, NH: Boynton/Cook Publishing. ISBN: 978-0867094589.

Carnell, E. (2007) 'Conceptions of Effective Teaching in Higher Education: Extending the Boundaries.' Teaching in Higher Education, 12(1), 25-40. Available at: https://doi.org/10.1080/13562510601102081 (Accessed: 18 May 2020).

Council of Writing Program Administrators. (2014, revised 2019) Outcomes Statement for FirstYear Composition (3.0). Available at:

wpacouncil.org/aws/CWPA/pt/sd/news_article/243055/_PARENT/layout_details/false (Accessed: 15 October 2020).

Foucault, M. (1977) Discipline and Punish. Translated by Alan Sheridan. New York: Pantheon Publishing. ISBN: 978-0679752554.

Giroux, H. (2001) 'Breaking into the Movies: Pedagogy and the Politics of Film.' JAC: A Journal of Composition Theory, 21(3) 583-598. Available at: https://www.jstor.org/stable/20866426 (Accessed: 18 May 2020).

Harris, J. (2017) Rewriting: How to Do Things with Texts. Boulder, CO: University Press of Colorado. ISBN: 978-0874216424.

Indiana University. (2020) 'Student Diversity.' University Institutional Research and Reporting. Available at: https://uirr.iu.edu/facts-figures/enrollment/diversity/index.html (Accessed: 15 October 2020).

Kubrick, S. (1980) The Shining. Los Angeles, CA: Warner Brothers.

Rosenwasser, D. and Stephen, J. (2011). Writing Analytically, 8th edition. Boston, MA: Cengage Learning, ISBN: 978-1337559461.

Shipka, J. (2011) Toward a Composition Made Whole. Pittsburgh, PA: University of Pittsburgh Press. ISBN: 978-0822961505. 
Von Trier, L. and Leth, J. (2003) The Five Obstructions. Hvidovre, Denmark: Zentropa Entertainments.

Wheeler, S. and Gerver, R. (2015) Learning with 'E's: Educational Theory and Practice in the Digital Age. Carmarthen, United Kingdom: Crown House Publishing. ISBN: 978-1845909390.

Wild, D.H. (1999) 'Writing Images: Some Notes on Film in the Composition Classroom.'

Cinema-(to)-graphy: Film and Writing in Contemporary Composition Courses, 22-31. Portsmouth, NH: Boynton/Cook Publishing. ISBN: 978-0867094589. 